\title{
Quality of Life of Older Persons in Indonesia: Sex Differences
}

\author{
I Komang Astina, PhD \\ Faculty of Social Science, State University of Malang, 65145 East Java, Indonesia \\ k_astina@yahoo.com \\ Wan Ibrahim Wan Ahmad, PhD \\ School of Social Development, Universiti Utara Malaysia, 06010 Sintok, Kedah, Malaysia \\ wiwa@uum.edu.my \\ Budiyanto, PhD \\ Faculty of Social Science, State University of Malang, 65145 East Java, Indonesia \\ budijanto19@yahoo.co.id
}

\section{Doi:10.5901/mjss.2015.v6n3s2p313}

\section{Abstract}

East Java province is one of the most populated provinces of older persons in Indonesia, and Kota Batu District occupied most of the older persons in the province. Most of older persons in Indonesia, including those who are residing in Kota Batu District, are poor. Kota Batu District is one of the districts that have a large number of older persons in Indonesia. Thus far not many research related to older persons has been conducted in the area. Although in recent years quality of life of the population has become a popular topic of discussion among academicians in Indonesia, quality of life of older persons has been a neglected area of study. Research on demography in Indonesia is still concentrated on younger population. Therefore, this paper is aimed at examining the level of quality of life of older persons aged 60 years and older. In particular, this study is aimed at exploring whether the level of quality of life is difference in terms of sex differences of older persons. Using a simple random sampling technique, a total of 300 older persons aged 60 years and older was selected. Data were gathered through face-to-face interviews using a questionnaire form, and analyzed descriptively. Result of the study show the majority of older persons in study area has a moderate level of quality of life, and there was no significant difference exist in the level of quality of life of old persons in terms of sex differences.

Keywords: Elderly person $•$ Family life $・$ Rural areas $•$ Job opportunities $•$ Gender

\section{Introduction}

The present paper presents a result of a cross-sectional survey on the quality of life of older persons conducted in Kota Batu District, East Java province, Indonesia. All societies throughout the world are now in their way towards an ageing society. Population ageing now is a global phenomenon. Recognizing the number older persons is increasing worldwide, research on older persons has become an important activity of academic staff of the universities whether in developed, or in developing countries as well. United Nations has also convened the World Assembly on Ageing in Vienna in 1982 to raise attention of public and policymakers alike the fact that all nations in the world are growing older (Ogawa, 1992). Through this assembly, the Vienna International Plan of Action, was agreed to be adopted to raise awareness of the government, policy makers, as well as individuals of all ages on the consequences of population ageing. Following the Vienna International Plan of Action, all countries are encouraged to give priority and serious attention on research related to older population.

\section{Objective of the Study}

The purpose of this paper is to examine the level of quality of life of older persons aged 60 years and older, and in particular, to explore whether sex differences has created difference level of quality of life of older persons in the district. 


\section{Literature Review}

Indonesia has recently experiencing the rapid growth of her older population. In 1980 for instance, the population aged 60 and over was 7999473 persons, which was 5.5\% out of the whole population of Indonesia. It has increased further to 14 440817 (7.2\%) in 2000, and is expected to reach 28.7 million (11.3\%) in 2020 (Tukiran Endang Ediastuti, 2004). One of the measures of population ageing is that the number of older population increases whilst at the same time the number of children and infant decrease. In Indonesia, a person is considered old when the person is aged 60 years and older. In the past, as the continuous increased in life expectancy and changes in retirement age, the limit was 55 . The growth of older population occurs concurrently with a decline of children or infant population. In 1971, the percentage of infant population aged 4 years and below was $16.1 \%$ of the total population. At that time the percentage of population aged 60 years and above was $4.5 \%$. In 2020 , its percentage will be $11.4 \%$ while the infant will be $6.9 \%$.

According to the words of Pawliczko and Troisi (2008), population ageing is not a gender-neutral. Because the mortality rate of male population over the life-course is higher, older women make up a majority of the world's older population. As in other parts of the world, the majority of older persons in Indonesia are also women. Women have always constituted more than $50 \%$ of older population and are projected to do so until 2050. Older women constitute an even higher proportion in the category of the oldest old. Women are no longer merely the main contributor to the household chores. For many women, the most important institution in her life is household, responsible for the care of the children and husbands. Due to the fact that rapid economic development and industrialization which have created lot of suitable jobs for women in the formal sectors, as well as in informal ones, couple with greater educational opportunities for women in recent years, women have become an important component of the labor force in Indonesia. Over the past decades, there has been a substantial increase in the absolute number of women entered in the labor force. This is particularly true as all over the world women make crucial contributions in agricultural settings, especially in developing countries as workers, farmers, as well as entrepreneurs. Despite this increase, women in traditional agriculture settings, particularly older women usually do not affected by such development. These older women usually work side by side with their husbands in substance agriculture, and at the same time they are also responsible for household tasks taking care for their husbands and children. Thus, from the observation, the division of labor in terms of gender does not clearly exist in rural areas.

Most of older persons in Indonesia are poor. Based on an international poverty line of USD 1 per capita per day, there were approximately two thirds of the world's poor, or around 800 million poor people lived in Asia and the Pacific region in 1998 (United Nations, 2002). It is estimated that around 70\% of the region's poor lives and works in rural areas (United Nations, 2007). The consequences of poverty are often more serious among older persons as they may have needs for medicines and health care than for those of working-age adults (United Nations, 2002). Poverty implies an inability to meet the basics of life ((United Nations, 2002), and thus it may affects the quality of life. Poverty is indeed likely to pose a profound impact on the quality of life. Observing on everyday experience very often people with low income will have a low level of quality of life.

Although in recent years quality of life has become a popular topic of discussion among academicians in Indonesia, quality of life of older persons has been a neglected area of study since much of research on demography in Indonesia is still concentrated on younger population. The concept of quality of life is central to gerontology. This is due to the fact that nowadays, there is increasing proportion of older people in community than in the past. Quality of life is a rapidly developing area of interdisciplinary research in gerontological and geriatrics care (Holmen, Erricson, and Winblad, 1999). In gerontological literature, the term quality of life achieved currency only in the last 10 or 12 years, and in an examination of 20 encyclopedias and dictionaries published in five world languages between 1968 and 1978, there was no single entry having quality of life as its subject (Szalai and Andrews, 1980). Although people tend to accept the quality of life as a multidimensional concept related to the person's satisfaction with various aspects of life, until now there is no agreed definition on this concept (Chan, Chiu, Chien, Thompson, and Lam, 2006).

The World Health Organization's Quality of Life Assessment Group defines quality of life as individual perception of their position in life in the context of the culture and the value system in which they live and in the relation to their goals, expectations, standards and concerns (WHOQOL Group, 1995; Bulter and Ciarrochi, 2007). Most scholars defined quality of life as the possession of resources necessary to the satisfaction of individual need, wants and desires, participation in activities enabling personal development and self-actualization and satisfactory comparison between oneself and others. While growing old is associated with a period declining in physical capacity and increased health risks and multiple psychosocial losses (Schilling, 2006), and it affect quality of life of older persons. There will be many changes occur when one enter old age. This time of life, people may facing many negative events, including decreased income, changes of health and physical functioning, as well as decrease in quality of life. Most of research conducted on 
quality of life suggests that such factors as income, health, marital status, gender, and age, among other factors, influencing quality of life (Bulter and Ciarrochi, 2007). Level of quality of life of older persons varies across these factors. This study is conducted to examine how far one of these factors, i.e. gender, has its influence on the quality of life of older persons.

\section{Materials and Methods}

The study for this paper is conducted in Kota Batu District, one of the districts that have a large number of the older persons in Indonesia. Particularly, material from which this paper is written is derived from a larger survey conducted in Kota Batu district, to explore the level of quality of life of the population aged 60 years and above, and to examine the factors behind it. One of the main reasons why this study was conducted in Kota Batu, is that the district is recorded to have a large number of older persons aged 60 years and older as compared to other districts.

This paper presents a small portion of the result in that study. The main objective of this paper is to examine whether the level of quality of life of older persons in Kota Batu District, East Java province, Indonesia is different in terms of sex differences.

Until recently there is no available research in the district exploring the influence of sex differences on the level of quality of life of older persons. As an agriculture area popular with vegetables, fruits and flowers, and all villagers regardless of sex is welcome to take part in the job available, the influence of sex on the level of quality of life needs to be explored. In doing this, three villages in the district were solicited as the study area. Prior to the study, a pilot study was conducted in all three villages to determine the number of older persons aged 60 years and older. From this pilot study, sampling frame for every village was set up. Using a simple random sampling technique, a total of 300 older persons were selected. Data were gathered through face-to-face interviews using a questionnaire form. Quality of life was assessed through a scale consisted of 11-item. Respondents were asked to indicate the extent to which each item was applicable to them using a four-point scale. To provide some insight into whether there is a significant different on the quality of life across sex, data were analyzed using t-test. T-test has been a tool to be using if we want to compare the means of quality of life of two samples.

\section{Results and Discussion}

This paper presents a small portion of a larger study on quality of life from samples of older persons aged 60 years and older in Kota Batu district, East Java province, Indonesia. Relevance to this paper is information on gender and quality of life. As we have observed on everyday life, we felt that the level of quality of life of older persons may be difference in terms of sex differences. This is because, among other things, the opportunity to get income and the freedom to enjoy the income is differ between men and women. Thus, it is important that what we have observed is tested statistically. Quality of life can be influenced by a variety of factors and the influence of sex differences is particularly important to be highlighted. In this paper the discussion is limited to the results of t-Test on the influence of sex differences on the quality of life of older persons in Kota Batu District, East Java province, Indonesia.

\subsection{Demographic Profiles}

Respondents of the study consisted of 322 older persons aged 60 years and older residing in Kota Batu District, East Java province, Indonesia. The percentage of older women is almost double compared to older men counterparts, with $67 \%$ women, and $33 \%$ men. They are all aged from the youngerst 60 years to the olderst 90 years old. The majority of the resppndents are aged 70 years and older. More than half (56\%) are currently married, and the majority of the currently married are women. Nearly half are widowed, and most of the widowed are also elderly women.

\subsection{Quality of Life of the Respondents}

Scores obtained from the scale employed in the study are categorized into three categories, namely (1) low level of quality of life (18-26), (2) moderate level of quality of life (27-35), and (3) high level of quality of life (36-44) (Table 1). Of the 322 older persons who responded to the survey conducted, only 36 of them have a low level of quality of life, and 61 of them have a moderate level of quality of life. The rest of the respondents (225) are having a moderate level of quality of life. Thus, this study found that the majority of the older persons in the study area are having a moderate level of quality of life. Though before the study it was expected that most of older persons in rural Indonesia has a low level 
quality of life, the finding of the study showed otherwise. Result of this survey is in line with the result of the survey conducted by Wan Ibrahim Wan Ahmad (1999) and Wan Ibrahim Wan Ahmad, Majidah Abd Majid \& Zainab Ismail (2014) on well-being of the older persons in Malaysia who also revealed that the majority of the older persons participated in the survey has a moderate level of well-being. A possible explanation of this finding could be that most of the older persons in the study area have their own sources of income that they do not face any serious problems to fulfill the basic needs of their family.

Table 1: Level of quality of life of Respondents

\begin{tabular}{|c|c|c|}
\hline Level of quality of life & Number & Percent \\
\hline Low & 36 & 11.2 \\
\hline Moderate & 225 & 69.9 \\
\hline High & 61 & 18.9 \\
\hline Number & 322 & 100.0 \\
\hline
\end{tabular}

\subsection{Quality of Life by Sex Dfiferences}

This paper is written to highlight the level of quality of life across sex differences. One might ask is there any differences in the level of quality of life in terms of sex differences? or does the quality of life differs significantly in terms of sex differences? According to calculated mean as shown in Table 2, analysis shows that the quality of life of women elderly has been slightly different with the men elderly counterparts, i.e. 31.1 (male), and 30.9 (female). The percentage of women elderly who has low and moderate level of quality of life is slightly higher. $12.0 \%$ of women elderly are categorized as having low level of quality of life as compared to only $10 \%$ from men elderly. In terms of moderate level of quality of life, women elderly has also experiences higher percentage. Men elderly has lower percentage in both categories, low and moderate level of quality of life. Thus, by these figures, it seems that there is a slightly difference of quality of life according to sex differences.

Tabel 2. Level of Quality of Life across Sex Dfiferences

\begin{tabular}{|c|c|c|c|c|}
\hline \multirow{2}{*}{ Sex } & \multicolumn{3}{|c|}{ Level of Quality of Life } & \multirow{2}{*}{ Mean } \\
\cline { 2 - 4 } & Low & Moderate & High & \\
\hline Male & $10(9.4)$ & $71(67.0)$ & $25(23.6)$ & 31.1 \\
Female & $26(12.0)$ & $154(71.3)$ & $36(16.7)$ & 30.9 \\
\hline
\end{tabular}

To detect whether there is a statistically significant difference exist across sex differences, the study proposed the hypothesis as "quality of life of older persons does not differ significantly in terms of sex differences". We first analyzed the difference through computed scores of different levels of quality of life. The analysis reveals that computed mean of quality of life of women elderly does not differ with men counterparts, i.e. 30.9 for women, and 31.1 for men. Differences in computed scores of different levels of quality of life is presented in Table 2.

Overall the number of elderly men who has a higher score of quality of life is not very much different from the number of elderly women in the same level of quality of life. As predicted, the result of t-test shows the level of quality of life of men elderly does not differ significantly from the level of quality of life of women elderly, $t(360)=0.440, p>0.05$. This statistics show that there is no significant difference of quality of life of older persons based on sex differences. This also to mean that the hypothesis stating "the quality of life of old persons do not differ significantly in terms of sex differences" is acceptable. To conclude, the results of the study found that the quality of life of women elderly did not differ significantly with the quality of life of men counterparts. They are likely to have the same level of quality of life.

\section{Discussion}

Indonesia has recently experiencing rapid growth of her older population (Wan Ibrahim Wan Ahmad, Asyraf $\mathrm{Hj}$ Ab Rahman, I Komang Astina and Budiyanto, 2013). With most of older persons are poor, the study of quality of life has become an urgent need to be conducted. The present paper is aim to explore the influence of sex differences on the level of quality of life. Evidences that have been gathered from research conducted outside Indonesia indicate that quality of life of older persons do not differ in terms of sex. Shin et.al (1983), for example, found the level of quality of life does not differ significantly in terms of sex. Wan Ibrahim Wan Ahmad (1999), who examined well-being of older persons in rural 
Malaysia, also found the level of well-being of older persons did not differ significantly in terms of sex. The result of the present study also shows the level of quality of life of both men and women elderly is not different. Analysis of t-test shows there is no difference exists between men and women in terms of quality of life. Thus, the insignificant difference in the level of quality of life based on sex differences as found in this study is in parallel with some of other studies outside Indonesia.

There are several reasons can be put forward. First, there is no discrimination of gender, particularly in terms of job opportunities. Men elderly and women have the same opportunities to get any job if available. Besides, although family life is still regarded as an important aspect of women's lives, they are given fully opportunity to be involved in employment outside the home. Furthermore, the present sample was made up of respondents who are involved in traditional agriculture setting where everyone is needed regardless of sex. Men and women are also both working as laborers and fruit pickers and harvesting vegetables. They have the same social statuses. With the same statuses, women elderly do not need to be dependent to their husbands. They have their own income to enjoy. These circumstances are eventually produces the same level of quality of life.

\section{Conclusion}

Following the rapid growing of older population in Indonesia in recent years, research on ageing and older persons has become an important agenda for scholars. Research on quality of life has been a new domain among academicians in Indonesia. Thus far not many research related to quality of life of older persons has been conducted in the area. Although in recent years quality of life has become a popular topic of discussion among academicians in Indonesia, quality of life of older persons has been a neglected area of study since much of research on demography in Indonesia is still concentrated on younger population and the problems they face. In an attempt to explore the quality of life of older persons, this study was conducted. This paper has provided some insight into the influence of gender on the quality of life of older persons in East Java province, Indonesia. Result of the study shows the majority of older persons have a moderate level of quality of life. Result of the study also shows the quality of life of older persons was not different in terms of sex differences. There are several reasons have been put forward to explain this, include such factors as no discrimination in terms of gender in terms of job opportunities, where men elderly and women elderly have the same opportunities to get any job if there is any.

\section{References}

Bulter, J. \& Ciarrochi, J. (2007). Psychological acceptance and quality of life in the elderly. Qual Life Res., 16: 607 - 615

Chan, Sally, Chiu, Hellen F. K., Chien, Wai-tong, Thompson, David R. \& Lam, Linda. (2006). Quality of life in Chinese elderly people with depression. International Journal of Geriatric Psychiatry, 21: 312 - 318

Holmen, K., Erricson, K., \& Winblad, B. (1999). Quality of life among the elderly: State of mood and loneliness in two selected groups. Scand J Caring Sci., 13: 91 - 95

Ogawa, N. (1992). "Resources for the elderly in economic development". In Hal L. Kendig et al. (eds.), Family support for the elderly. The international experience. Oxford: Oxford University.

Pawliczko, A.L., \& J. Troisi. (2008). The feminization of ageing in Asia, in Troisi \& Lencyk Pawliczko (eds). The elderly women in Asia: Her roles and position. Malta: United Nations.

Schilling, O. (2006). Development of life satisfaction in old age: Another view on the paradox. Social Indicators Research, 75 : 241 - 271

Shin, D. C. \& Johnson, D. M. (1978). Avowed happiness as an overall assessment of the quality of life. Social Indicators Research, 5: $475-92$

Szalai, A. \& Andrews, Frank M. (1980). The quality of life: Comparative study. London: Sage

Tukiran, E. Ediastuti. (2004). Penduduk Indonesia saat ini dan tantangan di masa mendatang, in Faturochman et al. (eds.) Dinamika kependudukan dan kebijakan. Yogyakarta: UGM.

United Nations. (2002). National policies and programs on ageing in Asia and the Pacific: An overview and lessons learned. Social Policy Paper No. 9. Bangkok: ESCAP

United Nations. (2007). Persistent and emerging issues in rural poverty reduction. Social Policy Paper No. 9. Bangkok: ESCAP

Wan Ibrahim. (1999). Social relationships, supports and well-being of elderly persons: A study in rural Kelantan. PhD thesis, Universiti Putra Malaysia (in Malay).

Wan Ibrahim, Asyraf, Hj. Ab. Rahman, I Komang Astina \& Budiyanto. (2013). Demographic aspect of older women in Indonesia. ANAS, 7 (4) Special: $401-404$.

Wan Ibrahim, Majidah Abd Majid \& Zainab Ismail. (2014). Subjective well-being of older persons at elderly day-care center. Middle-East Journal of Scientific Research 20 (11): 1461-1464

WHOQOL Group. (1995). The World Health Organization Quality of Life Assessment: Position paper from The World Health Organization. Social Science \& Medicine, 41 (10): 1403 - 1409. 